\title{
Assessing economic consequences of foot disorders in dairy cattle using a dynamic stochastic simulation model
}

\author{
M. R. N. Bruijnis, ${ }^{* 1}$ H. Hogeveen, $† \ddagger$ and E. N. Stassen* \\ *Wageningen Institute for Animal Sciences, Department of Animal Sciences, Animals and Society, Wageningen University, PO Box $338,6700 \mathrm{AH}$, \\ Wageningen, the Netherlands \\ †Department of Farm Animal Health, Faculty of Veterinary Medicine, Utrecht University, PO Box 80151, 3508 TD, Utrecht, the Netherlands \\ fBusiness Economics Group, Wageningen University, PO Box 8130, 6706 KN, Wageningen, the Netherlands
}

\section{ABSTRACT}

Foot disorders are an important health problem in dairy cattle, in terms of economics and animal welfare. The incidence, severity, and duration of foot disorders account for their importance. Prevalence of both subclinical and clinical foot disorders is high. More insight into the economic consequences could increase awareness among dairy farmers and could be an incentive for them to take action on this problem of animal welfare. The objective of this research was to estimate the economic consequences of different types of foot disorders, both clinical and subclinical. A dynamic stochastic Monte Carlo simulation model was used, taking into account the different types of foot disorders. The economic consequences of the foot disorders modeled were costs due to milk production losses, culling, prolonged calving interval, labor of the dairy farmer and the foot trimmer, visits of a veterinarian, treatment, and discarded milk. Under the milk quota system in the Netherlands, costs due to foot disorders for a default farm with 65 cows averaged $\$ 4,899$ per year (ranging from $\$ 3,217$ to $\$ 7,001$ ), an annual loss of $\$ 75$ per cow. This calculation implies that the costs due to foot disorders are more substantial than farmers might think. The costs of subclinical foot disorders account for $32 \%$ of all costs due to foot disorders. The costs due to foot disorders that are present without treatment or detection by the farmer are considerable. This finding implies that farmers might underestimate the benefits of taking action earlier and more thoroughly. A clinical foot disorder costs, on average, $\$ 95$, and a subclinical foot disorder $\$ 18$. The highest costs classified by foot disorder were those due to digital dermatitis, which has a high incidence and relatively high clinical prevalence. The highest costs classified by cost factor were those due to milk production losses and culling. Sensitivity analysis showed that variables regarding milk produc-

Received September 11, 2009

Accepted February 9, 2010.

${ }^{1}$ Corresponding author: Marielle.Bruijnis@wur.nl tion were important for economic costs due to foot disorders. Furthermore, the probability of getting a foot disorder and probability of cure were important for estimating the costs due to foot disorders. Farmer awareness concerning dairy cow foot health and taking action more thoroughly, therefore, could reduce the economic consequences and improve welfare simultaneously.

Key words: dairy cow, foot disorder, economic modeling, Monte Carlo simulation

\section{INTRODUCTION}

From both an economic and an animal welfare point of view, foot disorders are an important health problem in dairy cattle. The high incidence, severity, and duration of foot disorders account for their importance (Clarkson et al., 1996; Dyer et al., 2007; Frankena et al., 2009). Foot disorders and the resulting lameness cause serious economic losses for the farmer. Together with mastitis and reproductive problems, foot disorders are regarded as the most important health problem causing economic losses (Enting et al., 1997; Kossaibati and Esslemont, 1997).

Foot disorders are an important problem for dairy cows kept in cubicle housing systems (Clarkson et al., 1996; Somers et al., 2003; Cramer et al., 2008). Most of these foot disorders are subclinical (i.e., do not cause lameness; Clarkson et al., 1996; Espejo et al., 2006; Dyer et al., 2007). Studies into risk factors and possible intervention strategies are numerous (Bergsten, 2003; Somers et al., 2005a,b). Despite this amount of knowledge in the field of foot health of dairy cattle, there is no reduction in prevalence and incidence of foot disorders (Somers et al., 2003; Whay et al., 2003). Lameness control programs have not yet been successful. This is mainly because of lack of compliance in the program by the farmer and veterinarian (Bell et al., 2009). This is critical because improvement in dairy cow foot health depends primarily on the dairy farmer. More insight into the economic consequences of foot disorders can make the farmer more aware of the problem. A few cost 
estimations have been published (Enting et al., 1997; Kossaibati and Esslemont, 1997). These estimations are older and limited in their scope as they only look at lameness (clinical foot disorders), do not differentiate between different foot disorders, and do not take into account their duration.

Different types of foot disorders can be distinguished. Some foot disorders, such as digital dermatitis and interdigital phlegmon, are infectious and mainly related to the skin. Other foot disorders (e.g., sole hemorrhages and white line diseases) are caused largely by physical or metabolic disturbances and occur in the sole of the claw or are secondary in nature (e.g., sole ulcer and interdigital hyperplasia). Each of the foot disorders has a specific effect on the welfare of the dairy cow and on the economic consequences because they differ in incidence, severity, and duration.

The development of a disease and its detection by dairy farmers vary among the different foot disorders: some are detected easily, whereas others are difficult to detect. For example, interdigital phlegmon is a very acute foot disorder, and practically all cases are detected easily and treated successfully. This disorder occurs mostly on one leg at a time and makes cows visibly lame. It causes intense discomfort for the cow for a brief period. On the other hand, interdigital dermatitis and heel erosion develop slowly and commonly occur on both hind hooves. It causes increasing discomfort for the cow and milk production losses to the farmer for a longer period. The losses per day are relatively low but accumulate over a longer period. However, the detection of bilateral foot disorders is less probable. A cow with bilateral foot disorders walks tenderly rather than being obviously lame. This is part of the natural response of a cow, as a prey animal, to minimize the response to pain (O'Callaghan et al., 2003), and it adds to the underestimation of the problem of foot disorders, especially for bilateral foot disorders, because a cow then cannot relieve one painful foot. The objective of this study was to estimate the economic consequences of foot disorders in dairy cattle, taking into account clinical and subclinical foot disorders and the dynamics of different types of foot disorders, using a dynamic stochastic Monte Carlo simulation model.

\section{MATERIALS AND METHODS}

\section{Model Overview}

A dynamic discrete event Monte Carlo simulation model was developed. Monte Carlo simulation is a computer simulation technique in which a simulation model is run repeatedly. Specific values for the parameters in the model for each individual iteration are drawn from relevant distributions. The naturally occurring variation in a biological system can thus be encompassed. The dynamic stochastic model was developed in Excel (Microsoft Corp., Redmond, WA) using add-in software @Risk (Palisade Corporation, Ithaca, NY).

The basic stochastic process was carried out at the cow level. In the first step, the model simulated cow characteristics of a herd of 65 dairy cows. In the second step, the model simulated the dynamics of foot disorders per cow per month for 2 complete calendar years. In this way, a steady state situation was achieved at the beginning of yr 2. In the third step, the results from yr 2 were used for calculation of the economic consequences of the simulated foot disorders. The fourth step involved the summation of results for the herd of 65 cows. To obtain a stable mean outcome and to determine the variation between the herds, 500 herds were simulated.

Information for input variables for this dynamic discrete event model was derived from scientific literature or, if no literature was available, based on the authors' expertise. Literature was selected on relevancy and reliability, based on the number of herds and dairy cows in the study, the scoring methods used, and the breed of the cows and housing system. The model is described in more detail in the following paragraphs.

\section{Foot Disorders}

In this study, foot disorders are classified as subclinical or clinical based on experimental assessments (Manson and Leaver, 1988; Bicalho et al., 2007a). Obviously lame cows and cows walking tenderly were considered as lame cases. The following foot disorders were modeled: interdigital phlegmon (IP), interdigital dermatitis and heel horn erosion (IDHE), digital dermatitis (DD), sole hemorrhage (SoH), white line disease (WLD), sole ulcer (SUL), and interdigital hyperplasia (HYP). Interdigital phlegmon, IDHE, and DD are infectious foot disorders; SoH, WLD, SUL, and HYP are caused by physical or metabolic disturbances or are secondary by nature.

Interdigital phlegmon, also called interdigital necrobacillosis or foul in the foot, is an acute inflammation of the dermal layers of the interdigital space and adjacent coronary band associated with Fusobacterium necrophorum and causes a sudden, severe lameness (Blowey and Weaver, 2003). Interdigital dermatitis and heel horn erosion were taken together as in other studies (Somers et al., 2003); IDHE is an epidermitis of the interdigital skin extending to the dermis; in many cases, infection extends to the heel horn. It is an infectious disease caused by different organisms. Digital dermatitis, often called Mortellaro's disease, is an infection of the epider- 
mis of the hoof skin (Blowey and Weaver, 2003). Sole hemorrhage is the result of metabolic disturbances and physical damage due to overloading and pressure on the claw. In the literature, the terms "laminitis" and "sole hemorrhage" are used interchangeably. In this study, we classified sole hemorrhage, subclinical laminitis, laminitis, and chronic laminitis as SoH. Hemorrhages and lesions in the white line, mainly caused by physical damage, were categorized as WLD. Sole ulcer, also called pododermatitis circumscripta, is a secondary foot disorder and occurs after disorders such as $\mathrm{SoH}$ and IDHE or after trauma. As in the study by Somers et al. (2003), the term "sole ulcer" applies to all ulcers in the sole, toe, and heel. Interdigital hyperplasia, commonly referred to as tyloma and fibroma, originates as a reaction to long-lasting inflammation of the interdigital cleft or IDHE. The disorder is recognizable by proliferation of the interdigital skin.

\section{Simulation of Cow Characteristics}

In the model, in each iteration for each cow (i) in the herd, parity $\left(\mathbf{P a r}_{\mathbf{i}}\right)$, milk production $\left(\mathbf{M P} \mathbf{P}_{\mathbf{i}}\right)$, lactation value $\left(\mathbf{L V}_{\mathbf{i}}\right)$, stage of lactation $\left(\mathbf{L S}_{\mathbf{i}}\right)$, and calving interval $\left(\mathbf{C I}_{\mathbf{i}}\right)$ were determined. Parity was determined using a discrete distribution function and could have 4 categories $(1,2,3$, and 4 and higher):

$$
\begin{gathered}
\operatorname{Par}_{\mathrm{i}}=\text { Discrete }\left(\left[\operatorname{Ppar}_{1}, \operatorname{Ppar}_{2}, \operatorname{Ppar}_{3},\right.\right. \\
\left.\left.\operatorname{Ppar}_{\geq 4}\right],[1,2,3,4]\right),
\end{gathered}
$$

where $\mathrm{Ppar}_{1}, \mathrm{Ppar}_{2}, \mathrm{Ppar}_{3}$, and $\mathrm{Ppar}_{\geq 4}$ are the input variables for the probability of having parity $1,2,3$, and 4 and higher, respectively. Milk production $\left(\mathrm{MP}_{\mathrm{i}}\right.$; $\mathrm{kg} / 305 \mathrm{~d}$ ) for cow (i) was determined with a normal distribution function:

$$
\mathrm{MP}_{\mathrm{ik}}=\operatorname{Normal}\left(\mathrm{MPpar}_{\mathrm{ik}}, \mathrm{SDMPpar}_{\mathrm{ik}}\right) \text {, }
$$

where MPpar ${ }_{i k}$ is $M_{i}$ in parity $(k)$ and SDMPpar $_{i k}$ is the standard deviation of $\mathrm{MP}_{\mathrm{i}}$ in parity $(\mathrm{k})$. Given $\mathrm{MP}_{\mathrm{i}}$, for each cow in each month, the daily milk yield $(\mathrm{kg})$ is calculated using Wood's lactation curve (Wood, 1967). Using the 0.25 and 0.75 percentiles of $\mathrm{MP}_{\mathrm{i}}$, an $\mathrm{LV}_{\mathrm{i}}$ with 3 classes, low-, middle-, and high-producing dairy cows, was determined. The $\mathrm{LS}_{\mathrm{i}}$ (month after calving) in the first month of the second year was determined, where $\mathrm{LS}_{\mathrm{i}}$ can be $1, \ldots, 15$. A standard calving pattern was used to determine $\mathrm{LS}_{\mathrm{i}}$ :

$$
\mathrm{LS}_{\mathrm{i}}=\operatorname{Discrete}\left(\left[\mathrm{P}_{\mathrm{LS} 1}, \ldots, \mathrm{P}_{\mathrm{LS} 15}\right],[1, \ldots, 15]\right),
$$

where $\mathrm{P}_{\mathrm{LS} 1}, \ldots, \mathrm{P}_{\mathrm{LS} 15}$ are the probabilities for each possible stage of lactation. Calving interval $\left(\mathrm{CI}_{\mathrm{i}}\right)$ was determined using a Pert distribution function:

$$
\mathrm{CI}_{\mathrm{i}}=\operatorname{Pert}\left(\mathrm{CI}_{\min }, \mathrm{CI}_{\mathrm{ml}}, \mathrm{CI}_{\max }\right)
$$

where $\mathrm{CI}_{\min }$ is the minimum value, $\mathrm{CI}_{\mathrm{ml}}$ is the most likely, and $\mathrm{CI}_{\max }$ is the maximum value. Before calving, a cow was assumed to have a dry period of 2 mo.

\section{Dynamics of Foot Disorders}

Foot disorder dynamics were modeled according to Figure 1. In the model, in every month each cow had different transition probabilities, depending on the status of the previous month: 1) the probability of getting a foot disorder: probability of change from healthy to subclinical $\left(\mathbf{P}_{\mathbf{H S}}\right)$ or probability of change from healthy to clinical $\left.\left(\mathbf{P}_{\mathbf{H C}}\right) ; 2\right)$ the probability of being cured: probability of change from subclinical to healthy $\left(\mathbf{P}_{\mathbf{S H}}\right)$ or probability of change from clinical to healthy $\left(\mathbf{P}_{\mathbf{C H}}\right)$; 3) the probability of a transition from a subclinical foot disorder to a clinical foot disorder $\left(\mathbf{P}_{\mathbf{S C}}\right)$. The subclinical foot disorders had a probability of developing into the clinical phase after one or more months $\left(\mathrm{P}_{\mathrm{SC}}\right)$ or had a probability of cure after foot trimming $\left(\mathrm{P}_{\mathrm{SH}}\right)$. The clinical foot disorders had a certain probability for recovery due to treatment by the farmer, foot trimmer, or veterinarian during the year or after foot trimming $\left(\mathrm{P}_{\mathrm{CH}}\right)$ and a probability of culling due to the foot disor$\operatorname{der}\left(\mathbf{P}_{\mathbf{C u l}}\right)$. In this study, 2 foot trimming interventions per year were assumed as is the common practice in the Netherlands. For every month $(\mathrm{t}=1, \ldots, 24)$, cow $(\mathrm{i}=$ $1, \ldots, 65)$, and foot disorder $(\mathrm{j}=1, \ldots, 7)$, the state of foot disorder, culled $\left(\mathbf{C u l}_{\mathrm{ijt}}\right)$, clinical $\left(\mathbf{C}_{\mathrm{ijt}}\right)$, subclinical $\left(\mathbf{S}_{\mathrm{ijt}}\right)$, and healthy $\left(\mathbf{H}_{\mathrm{ijt}}\right)$, were determined with a set of discrete distribution functions:

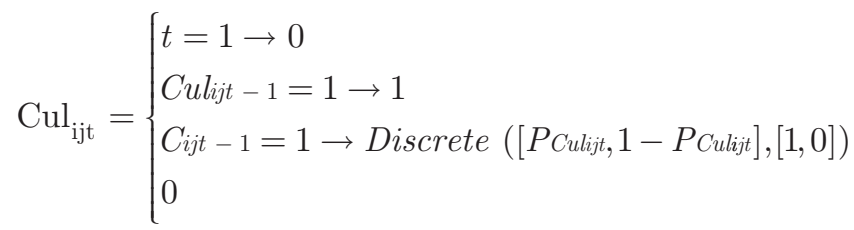

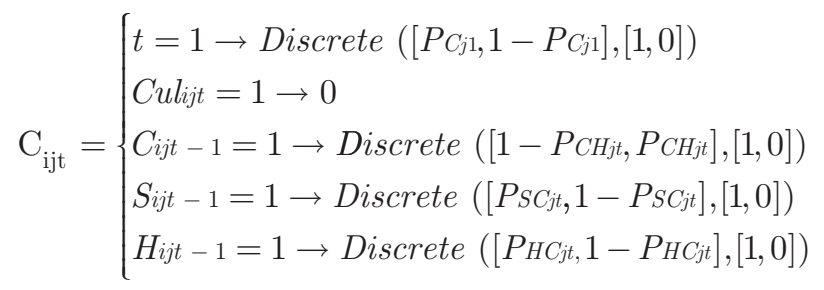




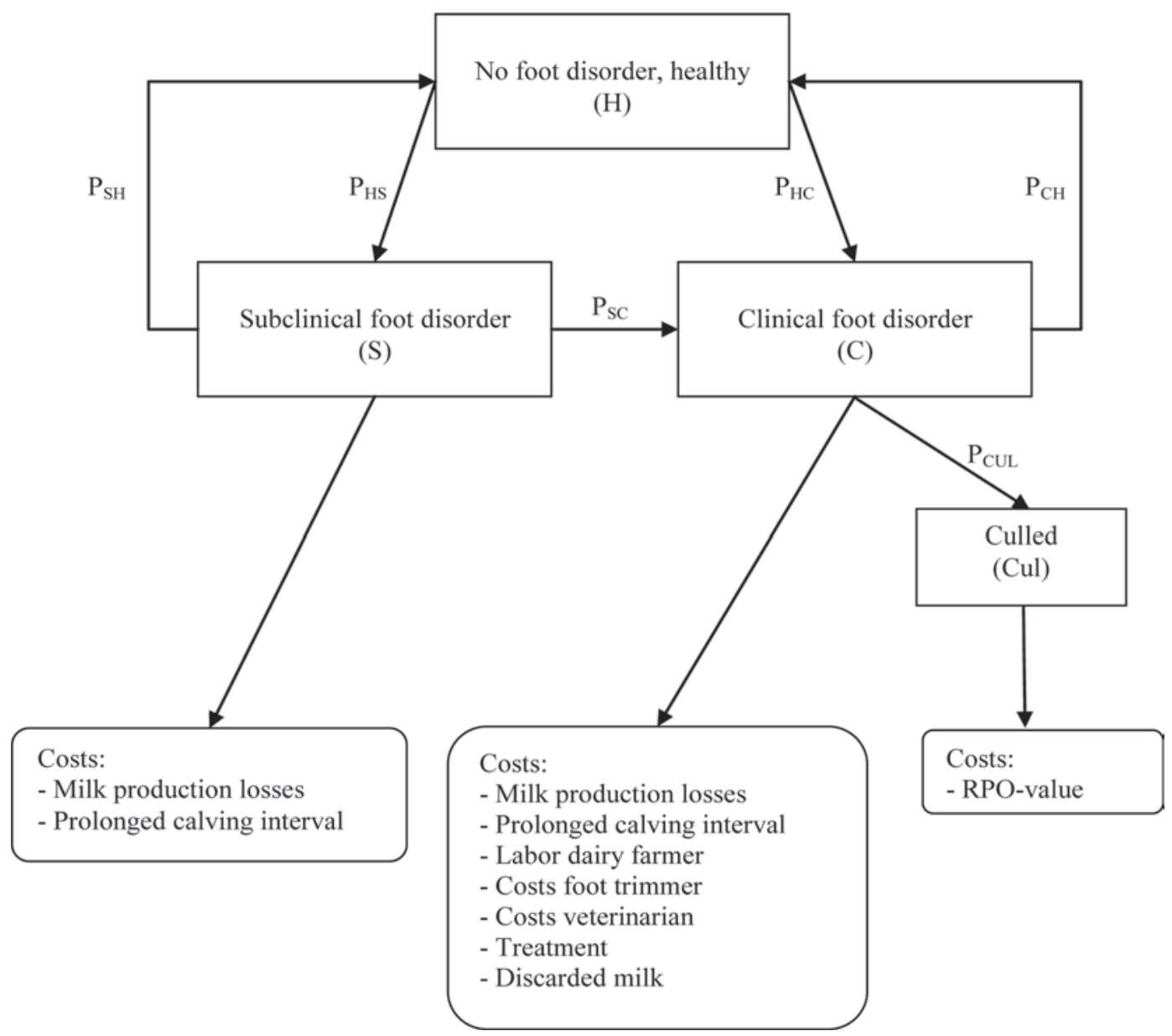

Figure 1. Schematic representation of the dynamics of the foot disorders in the dynamic stochastic simulation model on economic consequences of foot disorders. $\mathrm{P}_{\mathrm{HS}}=$ probability of change from healthy to subclinical; $\mathrm{P}_{\mathrm{HC}}=$ probability of change from healthy to clinical; $\mathrm{P}_{\mathrm{SH}}=$ probability of change from subclinical to healthy; $\mathrm{P}_{\mathrm{CH}}=$ probability of change from clinical to healthy; $\mathrm{P}_{\mathrm{SC}}=$ probability of transition from a subclinical foot disorder to a clinical foot disorder; $\mathrm{P}_{\mathrm{CUL}}=$ probability of culling; $\mathrm{RPO}=$ retention pay-off.

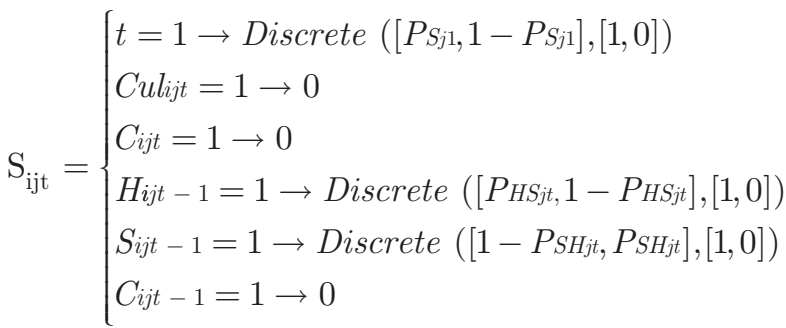

$$
\begin{aligned}
& \mathrm{H}_{\mathrm{ijt}}=\left\{\begin{array}{l}
t=1 \rightarrow \text { Discrete }\left(\left[P_{H j 1}, 1-P_{H j 1}\right],[1,0]\right) \\
\text { Culijt }=1 \rightarrow 0 \\
S_{i j t}=1 \rightarrow 0 \\
C_{i j t}=1 \rightarrow 0 \\
1
\end{array}\right.
\end{aligned}
$$

where $\mathrm{P}_{j 1}, \mathrm{P}_{j 1}$, and $\mathrm{P}_{j 1}$ are the probabilities for the different foot disorders $(\mathrm{j})$ for $\mathrm{t}=1$, the first month of

the first year. Other probabilities $\left(\mathrm{P}_{\mathrm{SC}}, \mathrm{P}_{\mathrm{SH}}, \mathrm{P}_{\mathrm{CH}}, \mathrm{P}_{\mathrm{HS}}\right.$, and $\mathrm{P}_{\mathrm{HC}}$ ) were explained previously and varied for the different foot disorders (j). The probabilities $\mathrm{PHS}_{\mathrm{ij}}(\mathrm{j}$ $=1, \ldots, 7)$ and $\operatorname{PHC}_{\mathrm{ij}}(\mathrm{j}=1, \ldots, 5)$ were dependent on $\operatorname{Par}_{\mathrm{i}}, \mathrm{LS}_{\mathrm{i}}, \mathrm{LV}_{\mathrm{i}}$, and month (t). For example, a higher producing cow has a higher risk of getting a foot disorder. $\mathrm{PCul}_{\mathrm{ijt}}$ was adjusted for lactation value and parity; a high-producing cow has less chance of being culled because of a foot disorder than a low-producing cow, and a high-parity cow has more chance of being culled than a young cow (Booth et al., 2004). Subsequently, whether cow (i) had a prolonged calving interval or not was modeled. We assumed that when a foot disorder occurs during the first 4 mo after calving, there is the probability of a prolonged calving interval $\left(\mathbf{P P C I}_{\mathbf{i}}\right)$.A prolonged calving interval consists of $21 \mathrm{~d}$. Only one prolongation of the calving interval can take place; $\mathrm{PPCI}_{\mathrm{i}}$ is given by

$$
\mathrm{PPCI}_{\mathrm{i}}=\text { Discrete }\left(\left[\mathrm{PPCI}_{\mathrm{i}}, 1-\mathrm{PPCI}_{\mathrm{i}}\right],[1,0]\right) \text {. }
$$


Table 1. Default input values for cow characteristics with their abbreviations and source

\begin{tabular}{llcl}
\hline Parameter & Abbreviation & Value (SD) & Source \\
\hline Farm size & $\mathrm{N}$ & 65 & CRV (2008); http://www.cr-delta.nl \\
$\begin{array}{l}\text { Distribution parities } \\
\text { Parity 1 }\end{array}$ & Ppar $_{1}$ & 0.32 & \\
Parity 2 & Ppar $_{2}$ & 0.25 & \\
Parity 3 & Ppar $_{3}$ & 0.18 & \\
Parity 4 and higher & Ppar $_{\geq 4}$ & 0.25 & \\
Mean milk production, kg/yr & MP1 & $7,434(437)$ & CRV (2008) \\
Parity 1 & MP2 & $8,666(510)$ & \\
Parity 2 & MP3 & $9,201(541)$ & \\
Parity 3 & MP4 & $9,156(539)$ & CRV (2008); http://www.cr-delta.nl \\
Parity 4 and higher & CI & 415 & \\
Calving interval, d &
\end{tabular}

\section{Calculation of Costs}

The model was built and run using values in Euros $(€)$. The values in the article were converted into US dollars (\$) using an exchange rate of $€ 1$ to US $\$ 1.41$. Total costs due to subclinical foot disorders $\left(\mathbf{T C}_{\mathbf{S C}}\right)$ and total costs due to clinical foot disorders $\left(\mathbf{T C}_{\mathbf{C}}\right)$ comprised costs for milk production losses $\left(\mathbf{C M P L}_{\mathrm{ijt}}\right)$, costs for culling $\left(\mathbf{C C U L}_{\mathrm{ijt}}\right)$, costs for prolonged calving interval $\left(\mathbf{C P C I}_{\mathbf{i j t}}\right)$, costs for labor of the dairy farmer $\left(\mathbf{C L a b D F}_{\mathrm{ijt}}\right)$, costs for the foot trimmer $\left(\mathbf{C F T}_{\mathrm{ijt}}\right)$, costs for the veterinarian $\left(\mathbf{C v}_{\mathbf{i j t}}\right)$, costs for treatment $\left(\mathbf{C T}_{\mathbf{i j t}}\right)$, and costs for discarded milk $\left(\mathbf{C D i s c}_{\mathrm{ijt}}\right)$. The costs were calculated monthly and summed up to a year for each cow. The costs for milk production losses due to subclinical and clinical foot disorders were based on milk production $\left(\mathrm{MP}_{\mathrm{i}}\right)$, the percentage of milk production loss (MPL), and costs for milk production losses $\left(\mathbf{C}_{\mathrm{MPL}}\right)$. Costs for a culled cow due to clinical foot disorder were based on the retention pay-off value (Houben et al., 1994) and were dependent on $\operatorname{Par}_{\mathrm{i}}$ and $\mathrm{LV}_{\mathrm{i}}$. Costs for a prolonged calving interval were calculated by multiplying the number of prolonged days with the costs for each day of prolongation. For clinical foot disorders, the extra labor of the dairy farmer was estimated in hours per month per cow. The costs were calculated by multiplying the hours with the hourly rate of a dairy farmer. Costs for the foot trimmer were calculated based on rates per treated cow, and costs for the veterinarian were calculated based on the price for a visit per treated cow. The costs for the use of antibiotics, costs for the resulting discarded milk, and topical treatments were included in the model as well. All these different costs were used to calculate the total costs for subclinical $(\mathrm{j}$ $=1, \ldots, 5)$ and clinical $(\mathrm{j}=1, \ldots, 7)$ foot disorders for a cow (i) during the months $(\mathrm{t}=13, \ldots, 24)$. The total costs (TC) due to foot disorders were

$$
\mathrm{TC}=\mathrm{TC}_{\mathrm{SC}}+\mathrm{TC}_{\mathrm{C}}
$$

where

$$
\mathrm{TC}_{\mathrm{SC}}=\sum_{i=1}^{65} \sum_{j=1}^{5} \sum_{j=1}^{5} C_{M P L i j t}+C_{P C I i j t}
$$

and

$$
\begin{aligned}
\mathrm{TC}_{\mathrm{C}} & =\sum_{i=1}^{65} \sum_{j=1}^{7} \sum_{t=13}^{24} C_{\text {MPLijt }}+\text { CCULijt }+ \text { CPCIijt } \\
& + \text { CLabDFijt }+ \text { CFTijt }+C_{\text {Vijt }}+C_{\text {Tijt }}+\text { CDiscijt. }
\end{aligned}
$$

\section{Default Input Data}

All peer-reviewed papers on prevalence, incidence, and consequences of foot disorders in dairy cattle were analyzed. Only those papers that applied to the criteria for default Dutch dairy circumstances were included. These criteria were cubicle housing system with a concrete (slatted) floor and mainly Holstein dairy cows. Authors' expertise was used when no scientific literature was available.

Cow Characteristics. Input on cow characteristics, herd composition, milk production, calving pattern, and calving interval are given in Table 1. These inputs were based on data from the Dutch cattle improvement organization (CRV).

Dynamics of Foot Disorders. Data on prevalence during foot trimming after summer and winter, scored by researchers, were used as the basis for input into the model (Somers et al., 2003). These data relate to cubicle housing systems with a concrete (slatted) floor, pasturing during summer, and 2 foot trimming interventions per year. Prevalence was adjusted for a cow having one foot disorder at a time, because additive calculation of the costs overestimates them, and the interdependence of the different foot disorders is not understood fully enough to correct for this overestimation. Foot disorders 
Table 2. Default input probabilities (\%) for the dynamics of foot disorders (FD) for the default farm ${ }^{1}$

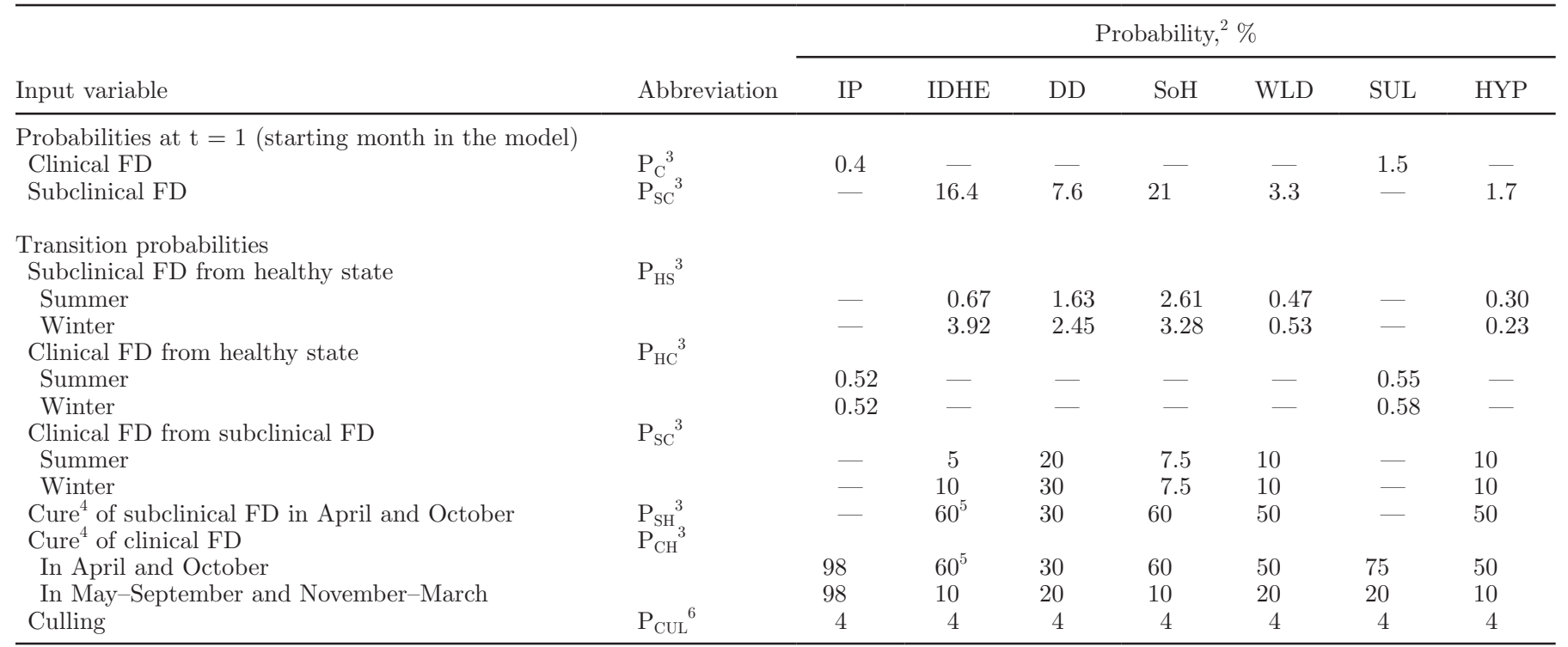

${ }^{1}$ Default farm: cubicle housing with concrete (slatted) floor, pasturing during summer (April through September), 2 foot trimming interventions per year (in April and October).

${ }^{2} \mathrm{IP}=$ interdigital phlegmon, IDHE = interdigital dermatitis and heel erosion, DD = digital dermatitis, SoH $=$ sole hemorrhage, WLD = white line disease, SUL = sole ulcer, HYP = interdigital hyperplasia. It is assumed that IP and SUL only occur as clinical foot disorders; the other foot disorders (DD, IDHE, SoH, WLD, and HYP) first occur as a subclinical foot disorder before transition to a clinical foot disorder occurs.

${ }^{3}$ Probabilities are estimated based on literature (Somers et al., 2003, 2005a,b; Holzhauer et al., 2006, 2008; Frankena et al., 2009) and the authors' expertise.

${ }^{4}$ Cure can occur as a result of treatment by a farmer, as a result of foot trimming, or after treatment by a veterinarian.

${ }^{5}$ The probability of cure after pasturing is $50 \%$.

${ }^{6}$ Applying to all clinical foot disorders based on Whitaker et al. (2004).

were classified as clinical and subclinical based on locomotion scores before and after foot trimming (Frankena et al., 2009) combined with information on pathology of different foot disorders (e.g., Somers et al., 2003). By using prevalence data on lame cows (using locomotion scores), we avoided overestimation of lameness. The locomotion scores before and after foot trimming were compared to estimate the cure rates after foot trimming. The different transition probabilities - transition from subclinical to clinical, cure of clinical foot disorders during the year, and probability of getting a new foot disorder - were estimated based on the scientific literature and the authors' expertise (Table 2). For the foot disorders having a subclinical and clinical state, it was assumed that the foot disorder first occurred as a subclinical foot disorder before transition to a clinical foot disorder.

All cases of IP and SUL were assumed to be clinical foot disorders. It was assumed that IP was (almost) always treated with antibiotics soon after a farmer identified a cow with IP and that treatment resulted in cure. Sole hemorrhages were scored based on the study by Somers et al. (2003), who scored the hemorrhages on density and extent of the hemorrhage. Slightly red discoloration, stripes or small spots, and moderate hemorrhage made up the subclinical cases. Severe hemorrhages and extended and acute red discoloration counted for clinical cases of $\mathrm{SoH}$ in the model. The division between clinical and subclinical lesions of DD and IDHE was based on the literature (Somers et al., 2003, 2005a,b; Holzhauer et al., 2006). Digital dermatitis thus followed the classification by Döpfer et al. (1997). The severity of IDHE was graded from 0 to 4 , where grade 4 and partly grade 3 were responsible for the lame and tender walking of cows in the model (Frankena et al., 2009). Based on the study by Somers et al. (2003), the early stage of WLD, white line separation, was classified as a subclinical foot disorder. The advanced stage of WLD, the white line abscess (when a white line separation has progressed to the level of the corium resulting in abscess formation), was assumed to cause lameness. The probability for a cow to be culled $\left(\mathrm{P}_{\mathrm{CUL}}\right)$ due to clinical foot disorders was $4 \%$ (adjusted after Whitaker et al., 2004). Culling due to subclinical foot disorders was not included in the model. Such culling is related to, for example, a prolonged calving interval, not to the foot disorder itself. In the values derived from Inchaisri et al. (C. Inchaisri, R. Jorritsma, P. L. 
A. M. Vos. G. C. van der Weijden, and H. Hogeveen; Department of Farm Animal Health, Faculty of Veterinary Medicine, Utrecht University, the Netherlands; unpublished data), which we used for estimation of costs due to prolonged calving interval, culling was already included. Dairy cows with clinical foot disorders, on average, have a calving interval prolonged by $12 \mathrm{~d}$ (Fourichon et al., 2000). The probability for having an extra cycle $(21 \mathrm{~d})$ in the model, therefore, is estimated to be $60 \%$. Subclinical foot disorders have less effect on calving interval; the probability of having an extra cycle due to a subclinical foot disorder is estimated to be $20 \%$ (Bicalho et al., 2007b).

Calculation of Costs. The estimates of milk production losses were based on the literature, which shows that high milk production and lameness are related. The references we used for our input estimates account for the fact that dairy cows with higher production have a higher risk for having foot disorders. The time a dairy farmer spends on treatment of a lame cow and the probabilities of treatment by dairy farmer, foot trimmer, and veterinarian were based on the authors' expertise (Table 3). Costs for milk production losses and discarded milk were estimated for the milk quota circumstances prevailing in the Netherlands (Huijps and Hogeveen, 2007). The value for a culled cow is dependent on parity and lactation value. The costs for prolonged calving interval were estimated to be $\$ 0.99$ per extra day, derived from Inchaisri et al. (C. Inchaisri, R. Jorritsma, P. L. A. M. Vos. G. C. van der Weijden, and H. Hogeveen; Department of Farm Animal Health, Faculty of Veterinary Medicine, Utrecht University, the Netherlands; unpublished data). The hourly rate for a dairy farmer, costs for a foot trimmer, and costs for a veterinarian were derived from the authors' expertise and Dutch standard values (KWIN-V, 2008-2009). Costs for topical treatment were based on the authors' expertise. It was assumed that only IP was treated with antibiotics, and that such treatment results in some days of withholding time for the milk (Table 4).

\section{Sensitivity Analysis}

A sensitivity analysis was performed to assess the effect of varying the input parameters on the total costs of foot disorders for our default farm. The sensitivity analysis was performed by adjusting the default values of selected parameters (Tables 1, 2, 3, and 4) to realistic alternatives, as described herein. The probabilities of getting a foot disorder $\left(\mathrm{P}_{\mathrm{HS}}\right.$ and $\left.\mathrm{P}_{\mathrm{HC}}\right)$ were increased and decreased by $50 \%$; the probability of transition to a clinical foot disorder from a subclinical foot disorder $\left(\mathrm{P}_{\mathrm{SC}}\right)$ was increased by $50 \%$. The probabilities of cure $\left(\mathrm{P}_{\mathrm{SH}}\right.$ and $\left.\mathrm{P}_{\mathrm{CH}}\right)$ on foot trimming were increased and de-

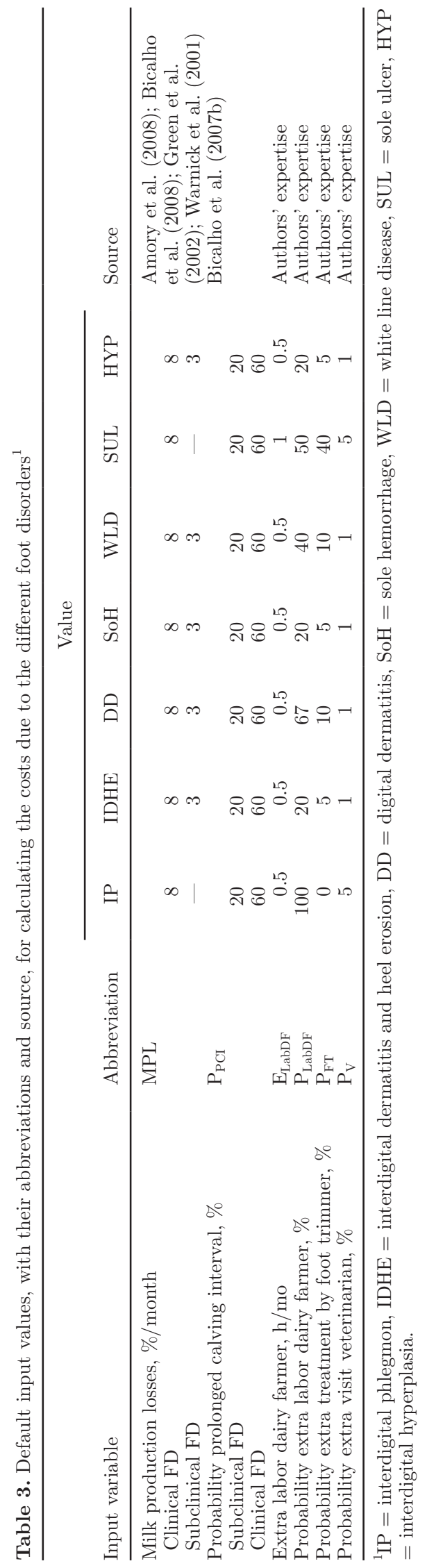

Journal of Dairy Science Vol. 93 No. 6, 2010 
Table 4. Default input values, with their abbreviations and source, for calculating the costs due to the different foot disorders

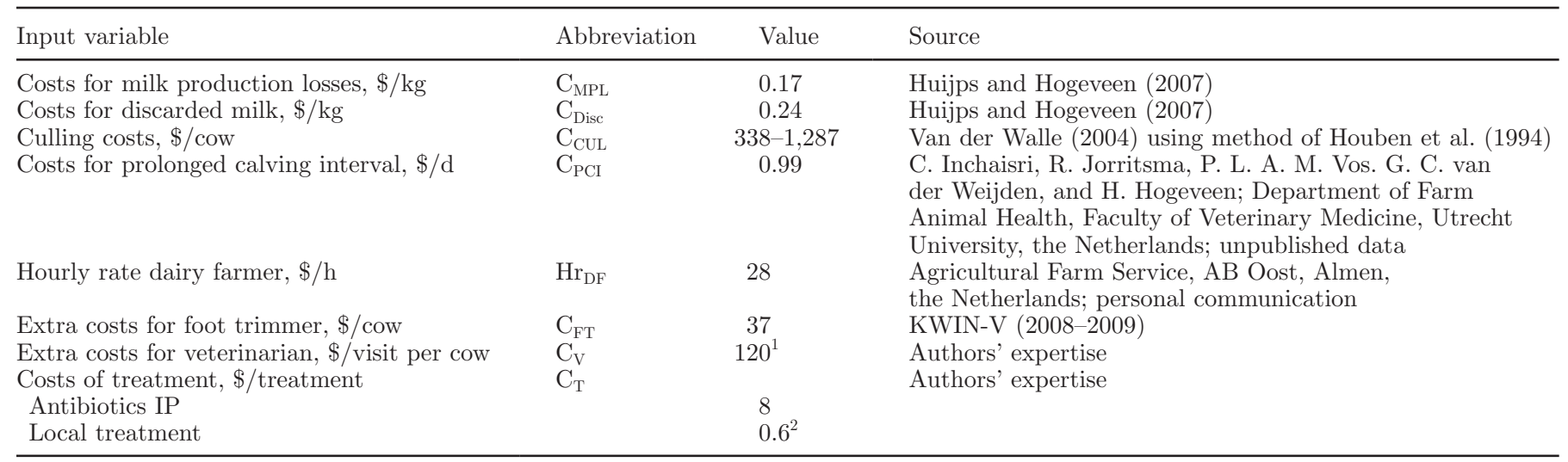

${ }^{1}$ For interdigital phlegmon (IP) there are only visit costs, estimated to be $\$ 42$; the visits for the other foot disorders also include labor of the veterinarian.

${ }^{2}$ Higher for sole ulcer (SUL) (2.3) and digital dermatitis (DD) (1.1) because of repeated cases and use of blocks for SUL.

creased by $25 \%$, and $\mathrm{P}_{\mathrm{CH}}$ during the year was increased by 10 percentage points. The probability of culling $\left(\mathrm{P}_{\mathrm{CUL}}\right)$ was doubled. The probability of prolonged calving interval $\left(\mathrm{P}_{\mathrm{PCI}}\right)$ for clinical foot disorders was increased to $70 \%$ and for subclinical foot disorders to $30 \%$. The costs of prolonged calving interval $\left(\mathrm{C}_{\mathrm{PCI}}\right)$ per day were decreased to $\$ 0.71 / \mathrm{d}$ and increased to $\$ 1.41 / \mathrm{d}$. Milk production losses were adjusted in 3 ways: MPL for the subclinical foot disorders were decreased to $1.5 \%$; MPL for the clinical foot disorders were decreased to $6 \%$; and MPL for the clinical claw lesions ( $\mathrm{SoH} \mathrm{C}, \mathrm{SUL}$, and WLD C) were increased to $12 \%$ (Amory et al., 2008). The costs for milk production losses $\left(\mathrm{C}_{\mathrm{MPL}}\right)$ were increased to $\$ 0.34$ (for a nonquota situation) and $\$ 0.10$ (for an extensive dairy farm under a quota situation). The extra labor of the dairy farmer $\left(\mathrm{E}_{\mathrm{LabDF}}\right)$ was increased by half an hour per month for every foot disorder, the probability of extra labor for the dairy farmer $\left(\mathrm{P}_{\mathrm{LabDF}}\right)$ was increased by 10 percentage points, the hourly rate for the dairy farmer $\left(\mathrm{Hr}_{\mathrm{DF}}\right)$ was decreased and increased by $\$ 14$. The probability of extra costs for a foot trimmer $\left(\mathrm{P}_{\mathrm{FT}}\right)$ was increased by 5 percentage points for all foot disorders; the costs for a foot trimmer $\left(\mathrm{C}_{\mathrm{FT}}\right)$ were increased to $\$ 54$ per treatment. The probability of an extra visit of a veterinarian $\left(\mathrm{P}_{\mathrm{V}}\right)$ was increased by 5 percentage points, and the costs for a visit of a veterinarian $\left(\mathrm{C}_{\mathrm{V}}\right)$ were increased by $\$ 14$. Herd composition was changed by having a higher proportion of older cows (parity $\geq 4$ ). The average 305 -d production per cow was increased by $1,000 \mathrm{~kg} / 305 \mathrm{~d}$.

\section{Default}

\section{RESULTS}

After running the model, the results showed that throughout the year the prevalence of foot disorders varied from $43 \%$ after foot trimming in October (af- ter grazing) to $80 \%$ at the end of the winter in March (before foot trimming; Figure 2). The prevalence of foot disorders per month showed that there is a clear effect of pasturing during summer and the foot trimming interventions on the prevalence of foot disorders. The prevalence of the foot disorders was highest at the end of the winter period. Figure 2 gives a graphical presentation of all foot disorders during the year. Subclinical $\mathrm{SoH}$ had the highest prevalence; SoH and IDHE were mainly subclinical, and only a few cases become clinical. This was also the case for the less prevalent foot disorders, WLD and HYP. The foot disorders IP and SUL had relatively low total prevalence, but did account for a substantial part of the total prevalence of clinical foot disorders. The foot disorder $\mathrm{SoH}$ had the most cases per year and had the longest duration (Table $5)$. Digital dermatitis had most cases that became clinical. The more severe foot disorders IP and SUL had a relatively short duration, but were responsible for $28 \%$ of all clinical cases. The total costs due to foot disorders for a farm with 65 cows in the default situation were $\$ 4,899$ per year ( $\$ 75$ per cow) with a range between $\$ 3,217$ and $\$ 7,001$. The costs due to subclinical foot disorders were $\$ 1,562$ per year (range between $\$ 1,245$ and $\$ 1,927$ ), which is $32 \%$ of the total costs due to foot disorders (Table 6). On average, a clinical case costs $\$ 95$ and a subclinical case $\$ 18$. Milk production losses caused $44 \%$ of the total costs due to foot disorders, culling $22 \%$, prolonged calving interval $12 \%$, and costs for extra labor of the dairy farmer $12 \%$. Interdigital phlegmon and SUL caused $23 \%$ of the total costs due to foot disorders (Table 7). Digital dermatitis had the greatest costs, mainly because of the relatively high incidence of the clinical stage. For SoH and IDHE, the subclinical stage had the highest cost. 


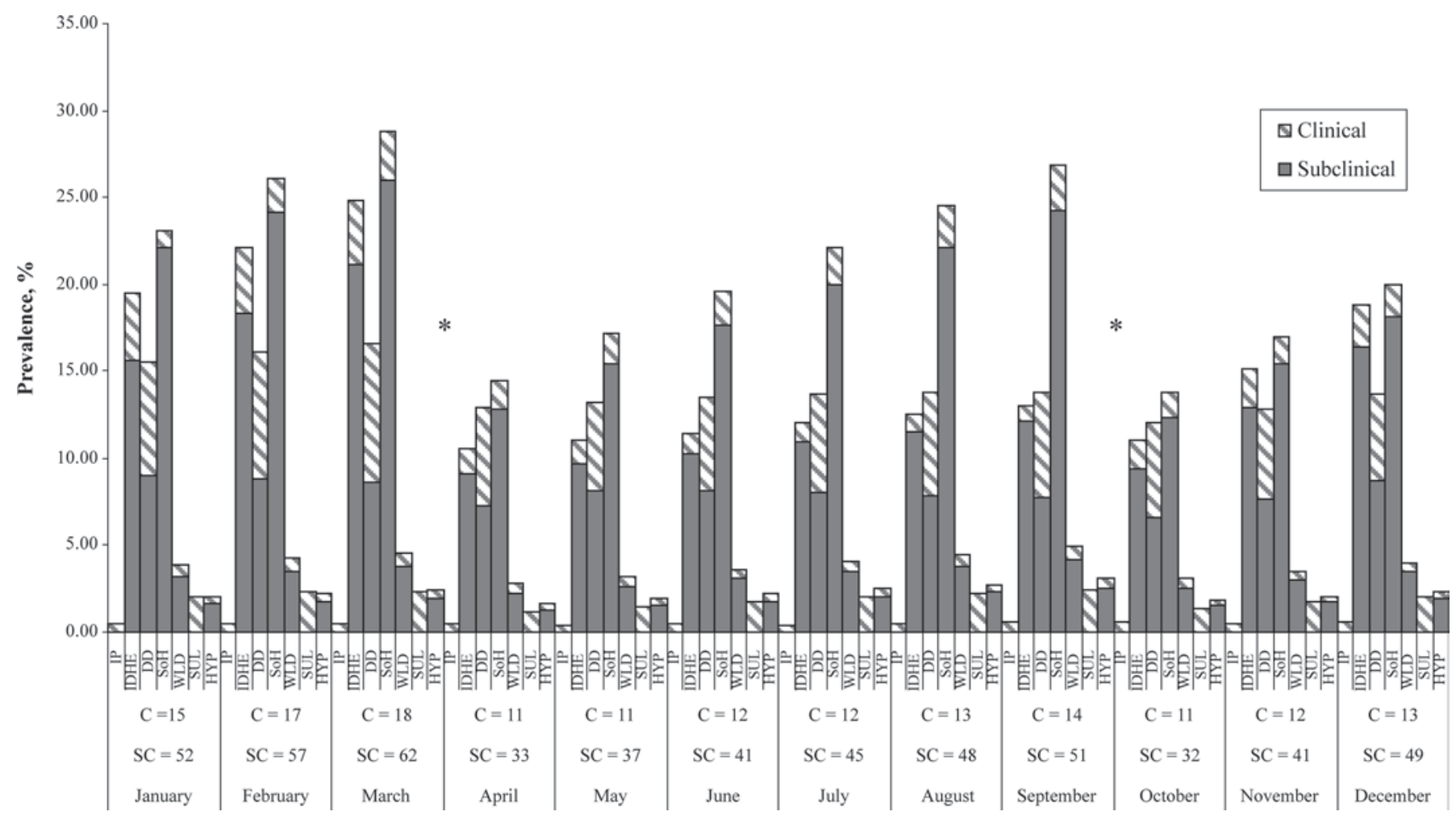

Figure 2. Average monthly prevalence of the different foot disorders, both subclinical (SC, solid bars) and clinical (C, hatched bars), on the default farm [cubicle housing with concrete (slatted) floor, pasturing during summer (April through September), 2 foot trimming interventions per year (in April and October)]. The months in which the foot-trimming interventions took place (in April after housing and in October after pasturing) are marked by *. Prevalence of subclinical and clinical foot disorders in these months represents the situation as measured after foot trimming. IP = interdigital phlegmon; IDHE = interdigital dermatitis and heel erosion; DD = digital dermatitis; SoH $=$ sole hemorrhage; WLD = white line disease; $\mathrm{SUL}=$ sole ulcer; $\mathrm{HYP}=$ interdigital hyperplasia; $\mathrm{C}=$ the total prevalence of clinical foot disorders in a month; $\mathrm{SC}=$ the total prevalence of subclinical foot disorders in a month.

\section{Sensitivity Analysis}

Sensitivity analysis showed that variables concerning milk production are important for the economic costs due to foot disorders. Total costs due to foot disorders on the default farm were most sensitive for variation in costs for milk production losses and discarded milk. Increased costs for milk production losses $(\$ 0.34)$ resulted in an increase of the total costs per year to $\$ 7,186$. Decreased costs for milk production losses $(\$ 0.10)$ resulted in a decrease of the total costs per year to $\$ 3,872$. Production level and percentage of milk production losses for the different foot disorders were also important, and, furthermore, the transition probabilities of the foot disorders were important. Probabilities of getting a foot disorder $\left(\mathrm{P}_{\mathrm{HS}}\right.$ and $\left.\mathrm{P}_{\mathrm{HC}}\right)$ resulted, with increased probability, in total costs of $\$ 6,748$ per year and, with decreased probability, in total costs of $\$ 2,800$ per year. Probabilities of cure $\left(\mathrm{P}_{\mathrm{SH}}\right.$ and $\left.\mathrm{P}_{\mathrm{CH}}\right)$ resulted, with increased probability, in total costs of $\$ 4,015$ per year and, with decreased probability, in total costs of $\$ 5,868$ per year. These variables, the probabilities of getting a foot disorder and cure of a foot disorder, determined the incidence and duration of the foot disorders. Variables with little effect $(<5 \%)$ are not shown (Figure 3$)$.

\section{DISCUSSION}

The dynamic stochastic Monte Carlo simulation model presented in this study adds much to existing model calculations because this model gives the opportunity to simulate the dynamics of different foot disorders, both clinical and subclinical. Previous economic studies were model-based as well, but were less specific, not taking into account subclinical foot disorders and the dynamics of different foot disorders (Enting et al., 1997; Kossaibati and Esslemont, 1997). In our model, economic consequences of foot disorders for the different types of foot disorder and for clinical and subclinical cases can be estimated. The model can be used for a variety of circumstances and different countries. The default input used in our model related to farms with cubicle housing systems with a concrete (slatted) floor, mainly Holstein dairy cows, pasturing 
Table 5. Incidence (cases/100 cows per year; 0.05 and 0.95 percentiles in parentheses) of subclinical and clinical foot disorders and duration per case (mo; 0.05 and 0.95 percentiles in parentheses) for the different foot disorders, subclinical and clinical, on the default farm ${ }^{1}$

\begin{tabular}{|c|c|c|c|c|c|c|c|}
\hline \multirow[b]{2}{*}{ Item } & \multicolumn{7}{|c|}{ Foot disorder ${ }^{2}$} \\
\hline & IP & IDHE & $\mathrm{DD}$ & $\mathrm{SoH}$ & WLD & SUL & HYP \\
\hline Subclinical & - & $\begin{array}{l}37 \\
(26 ; 49)\end{array}$ & $\begin{array}{l}27 \\
(18 ; 35)\end{array}$ & $\begin{array}{c}54 \\
(42 ; 66)\end{array}$ & $\begin{array}{l}9 \\
(5 ; 15)\end{array}$ & - & $\begin{array}{l}5 \\
(2 ; 9)\end{array}$ \\
\hline Clinical & $\begin{array}{l}6 \\
(2 ; 11)\end{array}$ & $\begin{array}{l}7 \\
(3 ; 12)\end{array}$ & $\begin{array}{c}20 \\
(12 ; 28)\end{array}$ & $\begin{array}{l}7 \\
(2 ; 12)\end{array}$ & $\begin{array}{l}3 \\
(0 ; 6)\end{array}$ & $\begin{array}{l}9 \\
(3 ; 15)\end{array}$ & $\begin{array}{l}2 \\
(0 ; 5)\end{array}$ \\
\hline \multicolumn{8}{|l|}{ Duration, mo } \\
\hline Clinical & $\begin{array}{l}1.02 \\
(1.00 ; 1.15)\end{array}$ & $\begin{array}{l}3.40 \\
(1.63 ; 5.75)\end{array}$ & $\begin{array}{l}3.54 \\
(2.38 ; 5.00)\end{array}$ & $\begin{array}{l}3.38 \\
(1.00 ; 6.25)\end{array}$ & $\begin{array}{l}2.90 \\
(1.00 ; 6.33)\end{array}$ & $\begin{array}{l}2.50 \\
(1.37 ; 4.00)\end{array}$ & $\begin{array}{l}4.01 \\
(1.00 ; 10.00)\end{array}$ \\
\hline
\end{tabular}

${ }^{1}$ Default farm: cubicle housing with concrete (slatted) floor, pasturing during summer (April through September), 2 foot trimming interventions per year (in April and October).

${ }^{2} \mathrm{IP}=$ interdigital phlegmon, IDHE $=$ interdigital dermatitis and heel erosion, $\mathrm{DD}=$ digital dermatitis, SoH $=$ sole hemorrhage, $\mathrm{WLD}=$ white line disease, SUL = sole ulcer, HYP = interdigital hyperplasia

during summer, and 2 foot trimming interventions per year. In case of doubt for input estimations or use of authors' expertise, we used conservative estimates to avoid overestimation.

In simulation modeling, estimates for input values are important. In our study, the literature was not always available that provided all the input values needed. Therefore, we needed to estimate input values as accurately as possible, based on the available literature and expertise. Using the outcomes from the available studies, we estimated the input as realistically as possible.

The results from the model show that the prevalence of all foot disorders (43 to 80\%) corresponded to the prevalence found in Dutch studies (e.g., Somers et al., 2003). This validates the estimated input values for input parameters on the dynamics of the different foot disorders that we could not derive directly from the literature. The prevalence of clinical foot disorders (11 to 18\%) was lower compared with that cited in the literature (Bicalho et al., 2007b; Frankena et al., 2009). The effects of pasturing and the foot trimming interventions were visible in the prevalence of the foot disorders (Figure 2). The prevalence of foot disorders increased more during winter (when cows were housed in cubicles) than during summer (when cows were pastured). When there are fewer subclinical foot disorders (due to foot trimming and pasturing) there will be fewer transitions to clinical foot disorders (preventive effect of foot trimming and pasturing). This was as-

Table 6. Economic consequences $(\$ / y r ; 0.05$ and 0.95 percentiles in parentheses) of subclinical and clinical foot disorders on the default farm ${ }^{1}$ classified by cost factors

\begin{tabular}{|c|c|c|c|}
\hline Costs related to: & Subclinical & Clinical & Total \\
\hline Milk production losses $\left(\mathrm{C}_{\mathrm{MPL}}\right)$ & $\begin{array}{l}1,219 \\
(994 ; 1,469)\end{array}$ & $\begin{array}{l}949 \\
(641 ; 1,349)\end{array}$ & $\begin{array}{l}2,168 \\
(1,729 ; 2,635)\end{array}$ \\
\hline Discarded milk $\left(\mathrm{C}_{\text {Disc }}\right)$ & $\begin{array}{l}0 \\
(0 ; 0)\end{array}$ & $\begin{array}{l}190 \\
(39 ; 377)\end{array}$ & $\begin{array}{l}190 \\
(39 ; 377)\end{array}$ \\
\hline Culling $\left(\mathrm{C}_{\mathrm{CUL}}\right)$ & $\begin{array}{c}0 \\
(0 ; 0)\end{array}$ & $\begin{array}{l}1,084 \\
\quad(0 ; 2,969)\end{array}$ & $\begin{array}{l}1,084 \\
\quad(0 ; 2,969)\end{array}$ \\
\hline Prolonged calving interval $\mathrm{C}_{\mathrm{PCI}}$ ) & $\begin{array}{l}343 \\
(207 ; 477)\end{array}$ & $\begin{array}{l}246 \\
(145 ; 373)\end{array}$ & $\begin{array}{l}589 \\
(415 ; 767)\end{array}$ \\
\hline Extra labor dairy farmer $\left(\mathrm{C}_{\mathrm{LabDF}}\right)$ & $\begin{array}{l}0 \\
(0 ; 0)\end{array}$ & $\begin{array}{l}578 \\
(353 ; 832)\end{array}$ & $\begin{array}{l}578 \\
(353 ; 832)\end{array}$ \\
\hline Extra visit foot trimmer $\left(\mathrm{C}_{\mathrm{FT}}\right)$ & $\begin{array}{c}0 \\
(0 ; 0)\end{array}$ & $\begin{array}{l}148 \\
(37 ; 293)\end{array}$ & $\begin{array}{l}148 \\
(37 ; 293)\end{array}$ \\
\hline Extra visit veterinarian $\left(\mathrm{C}_{\mathrm{V}}\right)$ & $(0 ; 0)$ & $\begin{array}{l}74 \\
(0 ; 240)\end{array}$ & $\begin{array}{l}74 \\
(0 ; 240)\end{array}$ \\
\hline Costs of treatment $\left(\mathrm{C}_{\mathrm{T}}\right)$ & $\begin{array}{c}0 \\
(0 ; 0)\end{array}$ & $\begin{array}{l}67 \\
(41 ; 96)\end{array}$ & $\begin{array}{l}67 \\
(41 ; 96)\end{array}$ \\
\hline Total (TC) & $\begin{array}{l}1,562 \\
(1,245 ; 1,927)\end{array}$ & $\begin{array}{l}3,337 \\
(1,736 ; 5,435)\end{array}$ & $\begin{array}{l}4,899 \\
(3,217 ; 7,001)\end{array}$ \\
\hline
\end{tabular}

${ }^{1}$ Default farm: cubicle housing with concrete (slatted) floor, pasturing during summer (April through September), 2 foot trimming interventions per year (in April and October). 


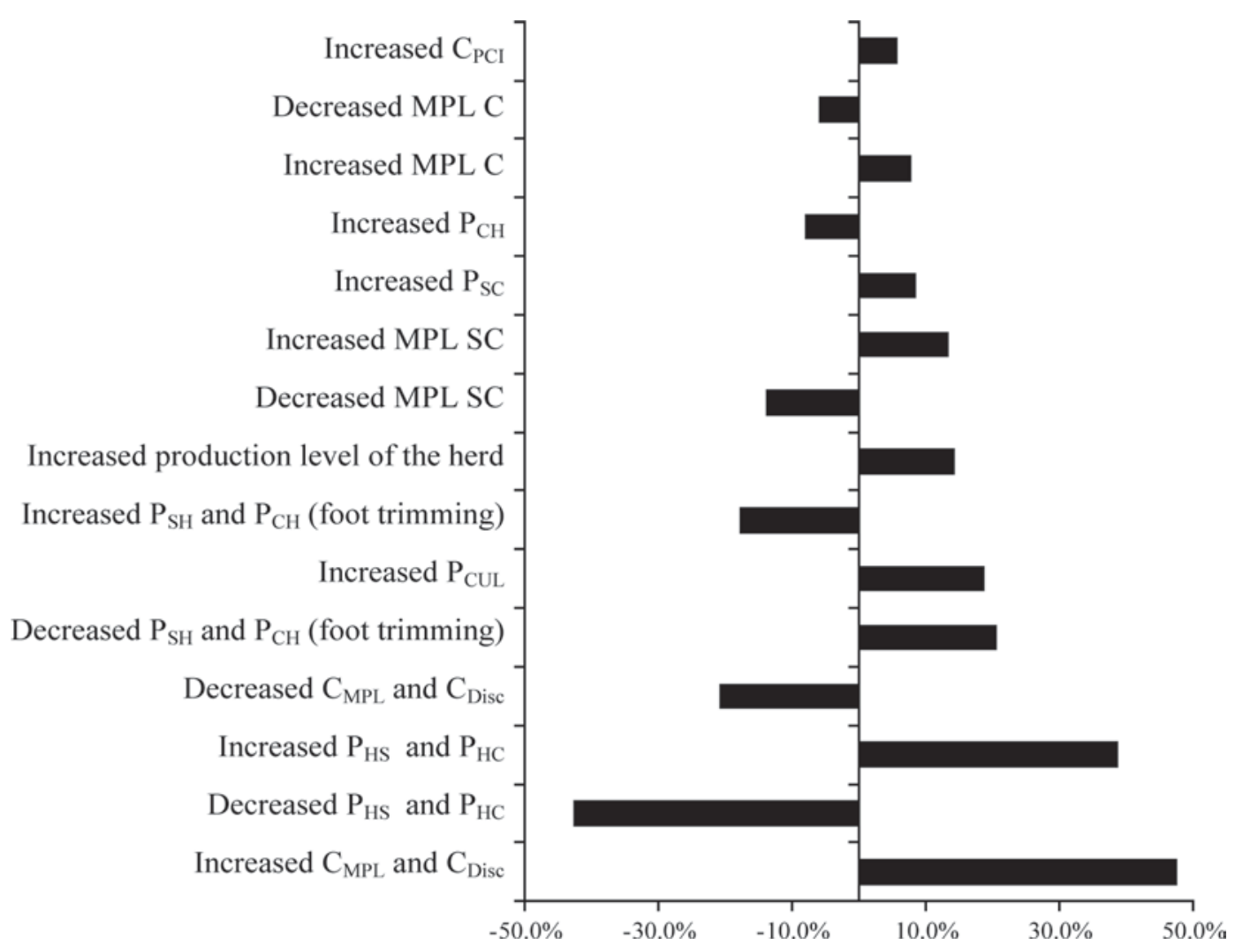

Figure 3. Most important results from the sensitivity analysis, showing the positive or negative effect of the changed variables on the costs due to foot disorders (\%). $\mathrm{C}_{\mathrm{MPL}}=$ costs of milk production losses; $\mathrm{C}_{\mathrm{Disc}}=$ costs of discarded milk; $\mathrm{P}_{\mathrm{HS}}=$ probability of change from healthy to subclinical; $\mathrm{P}_{\mathrm{HC}}=$ probability of change from healthy to clinical; $\mathrm{P}_{\mathrm{SH}}=$ probability of change from subclinical to healthy; $\mathrm{P}_{\mathrm{CH}}=$ probability of change from clinical to healthy; $\mathrm{P}_{\mathrm{CUL}}=$ probability of culling; MPL $\mathrm{SC}=$ milk production losses from subclinical foot disorders; MPL $\mathrm{C}=$ milk production losses from clinical foot disorders; $\mathrm{P}_{\mathrm{SC}}=$ probability of transition from a subclinical foot disorder to a clinical foot disorder; $\mathrm{C}_{\mathrm{PCI}}=$ costs prolonged calving interval.

sumed for the foot disorders IDHE, DD, SoH, WLD, and HYP, which first occur subclinically and then may become clinical. The effect of foot trimming on clinical foot disorders was less obvious than the effect on subclinical foot disorders. An explanation for this is that clinical foot disorders, unlike subclinical foot disorders, are treated throughout the year. The incidence of $54 \%$ for all clinical foot disorders in our model, which corresponds to the incidence found in the study of Clarkson et al. (1996), is lower than the incidence found in the study of Hedges et al. (2001) (69\%), and is higher than the incidence found in the studies of War-

Table 7. Economic consequences (\$/yr; 0.05 and 0.95 percentiles in parentheses) for the different foot disorders, subclinical and clinical, on the default farm ${ }^{1}$ classified by foot disorders

\begin{tabular}{lccccccc}
\hline & \multicolumn{5}{c}{ Foot disorder ${ }^{2}$} \\
\cline { 2 - 7 } Item & IP & IDHE & DD & SoH & WLD & SUL \\
\hline Subclinical & - & 441 & 269 & 667 & 116 & HYP \\
Clinical & & $(258 ; 631)$ & $(139 ; 403)$ & $(462 ; 899)$ & $(28 ; 236)$ & 68 \\
& 479 & 383 & 1,249 & 334 & 159 & 641 & $(4 ; 166)$ \\
Total & $(88 ; 1,316)$ & $(41 ; 1,352)$ & $(489 ; 2,481)$ & $(30 ; 1,232)$ & $(0 ; 893)$ & $(139 ; 1,624)$ & $(0 ; 345)$ \\
& 479 & 825 & 1,517 & 1,001 & 641 & $(56)$ \\
& $(88 ; 1,316)$ & $(396 ; 1,818)$ & $(731 ; 2,784)$ & $(601 ; 1,976)$ & $(53 ; 1,022)$ & $(139 ; 1,624)$ & $(9 ; 448)$ \\
\hline
\end{tabular}

${ }^{1}$ Default farm: cubicle housing with concrete (slatted) floor, pasturing during summer (April through September), 2 foot trimming interventions per year (in April and October).

${ }^{2} \mathrm{IP}=$ interdigital phlegmon, IDHE $=$ interdigital dermatitis and heel erosion, $\mathrm{DD}=$ digital dermatitis, SoH $=$ sole hemorrhage, $\mathrm{WLD}=$ white line disease, SUL = sole ulcer, HYP = interdigital hyperplasia. 
nick et al. (2001) and Bicalho et al. (2008). Differences in prevalence and incidence for the different clinical and subclinical foot disorders among different studies can be because of the subjective assessment of what is clinical and subclinical, and what is severely lame and (merely) lame, and how different foot disorders are defined and assessed. Several studies with low incidence would underestimate of the real incidence. Studies with low incidence are mainly based on farmer assessment or interval assessment by a veterinarian or a foot trimmer. Differences among studies also exist because of large variation between farms, farming systems, regions, and countries.

The total costs due to foot disorders for the default farm with 65 cows were $\$ 4,899$ per year - a total cost of $\$ 75$ per cow. Total costs at the herd level varied between $\$ 3,217$ and $\$ 7,001$. The subclinical foot disorders accounted for $32 \%$ of these costs. In the model, the costs for the 2 foot trimming interventions were not taken into account ( $\$ 14$ per cow per year). Foot trimming is partly preventive (reducing costs due to foot disorders by prevention of new subclinical foot disorders and prevention of transition of subclinical to clinical foot disorders) and partly curative (direct costs for the cure of subclinical and clinical foot disorders). Taking into account the curative costs, the total costs due to foot disorders on the default farm increased by approximately $\$ 7$ per cow per year. This increase resulted in a total cost of $\$ 82$ per cow. The foot trimming interventions, performed by qualified, trained foot trimmers, have a great influence on the prevalence of foot disorders (Figure 2). A positive effect of foot trimming is also indicated by Sogstad et al. (2007), where milk production increased after foot trimming. Without foot trimming interventions, the prevalence of foot disorders, subclinical and clinical, would be higher (Manske et al., 2002). A higher prevalence of foot disorders results in more costs due to these foot disorders. For example, there would be higher costs for culling due to higher prevalence of clinical foot disorders.

After mastitis, which costs $\$ 110$ per average cow in the herd (Huijps et al., 2008), foot disorders cause substantial costs for the dairy farmer. Results from an earlier Dutch study gave $\$ 32$ per average cow in the herd for lameness (Enting et al., 1997). The calculation of these costs did not take into account the costs due to subclinical foot disorders and the dynamics of various foot disorders. Furthermore, a low level of production losses was found. The new calculation in our study implies that the costs due to foot disorders are more substantial than farmers might think. However, compared with the results of Kossaibati and Esslemont (1997), the costs found in our study were lower. In that study, it was assumed, for example, that SUL involved higher milk production losses, higher risk of culling, a longer calving interval, and a higher prevalence compared with other foot disorders. In our study, there was no differentiation in milk production losses, risk of culling, or calving interval for the different foot disorders, because there was no scientific literature available to make this input specific for the different foot disorders. In our model, therefore, there was no distinction between the infectious and the physical foot disorders for milk production losses. Information on this is ambiguous (Warnick et al., 2001; Green et al., 2002; Amory et al., 2008). A better estimation of the economic consequences of foot disorders requires more specific information about the effects of the different foot disorders on, for example, milk production losses and culling decisions. The effects of different gradations of foot disorders and the effects of foot disorders before and after diagnosis and treatment are also required for a better estimation of their economic consequences. The effects of foot disorders differ among cows, farms, and countries, and development of foot disorders differs between cows. In one cow, for example, a foot disorder progresses faster than in another cow. Differences between farms originate in the varied management practices of the farmer. Detection and treatment of foot disorders by farmers vary according to the attitude of the farmer. Some farmers, for example, will detect a cow with a foot disorder earlier and treat the cow more precisely than other farmers. Regulations concerning treatment differ between countries and influence the timing and the precision of treatment. Treatment by a veterinarian, for example, is compulsory and subsidized in certain countries. These differences have great influence on the above-mentioned effects of foot disorders. Our model can be adjusted for these specific circumstances. Modeling specific circumstances in dairy husbandry, using specific input values, will be valuable.

Studies on the relationship between the prevalence of different foot disorders at any one time are available (e.g., Holzhauer et al., 2006; Capion et al., 2008). However, these data are not precise enough to use in this model. Therefore, relationships between foot disorders were not modeled and it was assumed that a cow could only have one foot disorder at a time. This assumption has a limited effect on the calculated costs, because the presence of two foot disorders at the same time does not cause twice as much in terms of production losses or a doubled probability of culling or a doubly prolonged calving interval.

In our study, foot disorders were classified as subclinical or clinical based on experimental assessment (Manson and Leaver, 1988; Bicalho et al., 2007a). Obviously lame cows and cows walking tenderly were considered lame cases. As the literature shows, dairy 
farmers detect lameness less frequently than do researchers (Espejo et al., 2006). However, the costs due to foot disorders that are present without treatment or detection by the farmer are considerable. This finding implies that farmers might underestimate the benefits of taking action earlier and more thoroughly. Greater effort by the farmer in an early stage could, at minimum, prevent production losses, reduce probability of culling, and result in less effect on the calving interval of dairy cows. This observation is supported by the results from the sensitivity analysis, which showed that the prevalence and incidence of foot disorders, determined by $\mathrm{P}_{\mathrm{HS}}, \mathrm{P}_{\mathrm{HC}}, \mathrm{P}_{\mathrm{SH}}$, and $\mathrm{P}_{\mathrm{CH}}$, have considerable impact on the costs due to foot disorders. The accuracy of the estimation of the costs due to foot disorders will improve with more information on 1) lameness detection specific to the different foot disorders; 2) the percentage of farmers who will take action at certain degrees of severity of different foot disorders; 3) how quickly farmers will take action; and 4) the resulting cure rates and recovery times.

The information on costs due to foot disorders can increase the awareness of dairy farmers with respect to foot disorders as a health and welfare problem in dairy cattle. More awareness could stimulate an increase of quality and frequency of taking measures to reduce the prevalence of foot disorders. This will be beneficial for the dairy farmer in economic terms and for the dairy cow in terms of health and welfare.

\section{CONCLUSIONS}

The dynamic stochastic Monte Carlo simulation model developed in this study gives an estimation of the economic consequences of foot disorders in dairy cattle, applicable for varying situations. Total costs due to foot disorders on the default farm under Dutch circumstances with 65 cows were $\$ 4,899$ per year $(\$ 75$ per cow), ranging from $\$ 3,217$ to $\$ 7,001$. This calculation implies that costs due to foot disorders are more substantial than farmers might think. Subclinical foot disorders caused $32 \%$ of the total costs due to foot disorders. Costs due to foot disorders that are present without treatment or detection by the farmer are considerable. This finding implies that farmers might underestimate the benefits of taking action earlier and more thoroughly. This study showed that, besides milk production losses, costs for milk production losses and costs for discarded milk, the incidence of the foot disorders and the probability of cure have a great impact on the economic consequences of foot disorders. More awareness and more thorough action by farmers concerning dairy cow foot health could reduce the economic consequences and improve health and welfare.

\section{ACKNOWLEDGMENTS}

We thank E. M. Kannekens (Faculty of Veterinary Medicine, Utrecht University, the Netherlands) and M. Holzhauer (Animal Health Service, the Netherlands) for sharing their expertise on foot disorders in dairy cattle.

\section{REFERENCES}

Amory, J. R., Z. E. Barker, J. L. Wright, S. A. Mason, R. W. Blowey, and L. E. Green. 2008. Associations between sole ulcer, white line disease and digital dermatitis and the milk yield of 1824 dairy cows on 30 dairy cow farms in England and Wales from February 2003-November 2004. Prev. Vet. Med. 83:381-391.

Bell, N. J., M. J. Bell, T. G. Knowles, H. R. Whay, D. J. Main, and A. J. F. Webster. 2009. The development, implementation and testing of a lameness control programme based on HACCP principles and designed for heifers on dairy farms. Vet. J. 180:178-188.

Bergsten, C. 2003. Causes, risk factors, and prevention of laminitis and related claw lesions. Acta Vet. Scand. 44:S157-S166.

Bicalho, R. C., S. H. Cheong, G. Cramer, and C. L. Guard. 2007a. Association between a visual and an automated locomotion score in lactating Holstein cows. J. Dairy Sci. 90:3294-3300.

Bicalho, R. C., F. Vokey, H. N. Erb, and C. L. Guard. 2007b. Visual locomotion scoring in the first seventy days in milk: Impact on pregnancy and survival. J. Dairy Sci. 90:4586-4591.

Bicalho, R. C., L. D. Warnick, and C. L. Guard. 2008. Strategies to analyze milk losses caused by diseases with potential incidence throughout the lactation: A lameness example. J. Dairy Sci. 91:2653-2661.

Blowey, R. W., and A. D. Weaver. 2003. Locomotor disorders. Pages 83-122 in Color Atlas of Diseases and Disorders of Cattle. 2nd ed. Mosby, New York, NY.

Booth, C. J., L. D. Warnick, Y. T. Grohn, D. O. Maizon, C. L. Guard, and D. Janssen. 2004. Effect of lameness on culling in dairy cows. J. Dairy Sci. 87:4115-4122.

Capion, N., S. M. Thamsborg, and C. Enevoldsen. 2008. Prevalence of foot lesions in Danish Holstein cows. Vet. Rec. 163:80-85.

Clarkson, M. J., D. Y. Downham, W. B. Faull, J. W. Hughes, F. J. Manson, J. B. Merritt, R. D. Murray, W. B. Russell, J. E. Sutherst, and W. R. Ward. 1996. Incidence and prevalence of lameness in dairy cattle. Vet. Rec. 138:563-567.

Cramer, G., K. D. Lissemore, C. L. Guard, K. E. Leslie, and D. F. Kelton. 2008. Herd- and cow-level prevalence of foot lesions in Ontario dairy cattle. J. Dairy Sci. 91:3888-3895.

CRV. 2008. www.cr-delta.nl. CRV, Arnhem, the Netherlands.

Döpfer, D., A. A. H. M. ter Huurne, J. L. Cornelisse, A. J. A. M. van Asten, A. Koopmans, F. A. Meijer, Y. H. Schukken, I. Szakall, W. Klee, and R. B. Bosma. 1997. Histological and bacteriological evaluation of digital dermatitis in cattle, with special reference to spirochaetes and Campylobacter faecalis. Vet. Rec. 140:620-623.

Dyer, R. M., N. K. Neerchal, U. Tasch, Y. Wu, P. Dyer, and P. G. Rajkondawar. 2007. Objective determination of claw pain and its relationship to limb locomotion score in dairy cattle. J. Dairy Sci. 90:4592-4602.

Enting, H., D. Kooij, A. A. Dijkhuizen, R. B. M. Huirne, and E. N. Noordhuizen-Stassen. 1997. Economic losses due to clinical lameness in dairy cattle. Livest. Prod. Sci. 49:259-267.

Espejo, L. A., M. I. Endres, and J. A. Salfer. 2006. Prevalence of lameness in high-producing Holstein cows housed in freestall barns in Minnesota. J. Dairy Sci. 89:3052-3058.

Fourichon, C., H. Seegers, and X. Malher. 2000. Effect of disease on reproduction in the dairy cow: A meta-analysis. Theriogenology 53:1729-1759.

Frankena, K., J. G. C. J. Somers, W. G. P. Schouten, J. V. van Stek, J. H. M. Metz, E. N. Stassen, and E. A. M. Graat. 2009. The effect of digital lesions and floor type on locomotion score in Dutch dairy cows. Prev. Vet. Med. 88:150-157. 
Green, L. E., V. J. Hedges, Y. H. Schukken, R. W. Blowey, and A. J. Packington. 2002. The impact of clinical lameness on the milk yield of dairy cows. J. Dairy Sci. 85:2250-2256.

Hedges, J., R. W. Blowey, A. J. Packington, C. J. O'Callaghan, and L. E. Green. 2001. A longitudinal field trial of the effect of biotin on lameness in dairy cows. J. Dairy Sci. 84:1969-1975.

Holzhauer, M., C. J. M. Bartels, D. Döpfer, and G. van Schaik. 2008. Clinical course of digital dermatitis lesions in an endemically infected herd without preventive herd strategies. Vet. J. 177:222230.

Holzhauer, M., C. Hardenberg, C. J. M. Bartels, and K. Frankena 2006. Herd- and cow- level prevalence of digital dermatitis in the Netherlands and associated risk factors. J. Dairy Sci. 89:580588.

Houben, E. H. P., R. B. M. Huirne, A. A. Dijkhuizen, and A. R Kristensen. 1994. Optimal replacement of mastitic cows determined by a hierarchic Markov process. J. Dairy Sci. 77:2975-2993.

Huijps, K., and H. Hogeveen. 2007. Stochastic modelling to determine the economic effects of blanket, selective, and no dry cow therapy. J. Dairy Sci. 90:1225-1234.

Huijps, K., J. G. M. Lam, and H. Hogeveen. 2008. Costs of mastitis: Facts and perception. J. Dairy Sci. 75:113-120.

Kossaibati, M. A., and R. J. Esslemont. 1997. The costs of production diseases in dairy herds in England. Vet. J. 154:41-51.

KWIN-V. 2008-2009. Kwantitatieve informatie veehouderij (Quantitative information on animal husbandry). Informatie en Kenniscentrum Veehouderij, Ede, the Netherlands.

Manske, T., J. Hultgren, and C. Bergsten. 2002. The effect of claw trimming on the hoof health of Swedish dairy cattle. Prev. Vet. Med. 54:113-129.

Manson, F. J., and J. D. Leaver. 1988. The influence of concentrate amount on locomotion and clinical lameness in dairy cattle. Anim. Prod. 47:185-190.
O'Callaghan, K. A., P. J. Cripps, D. Y. Downham, and R. D. Murray 2003. Subjective and objective assessment of pain and discomfort due to lameness in dairy cattle. Anim. Welf. 12:605-610.

Sogstad, A. M., O. Osteras, T. Fjeldaas, and A. O. Refsdal. 2007. Bovine claw and limb disorders at claw trimming related to milk yield. J. Dairy Sci. 90:749-759.

Somers, J. G. C. J., K. Frankena, E. N. Noordhuizen-Stassen, and J. H. M. Metz. 2003. Prevalence of claw disorders in Dutch dairy cows exposed to several floor systems. J. Dairy Sci. 86:2082-2093.

Somers, J. G. C. J., K. Frankena, E. N. Noordhuizen-Stassen, and J. H. M. Metz. 2005a. Risk factors for digital dermatitis in dairy cows kept in cubicle houses in the Netherlands. Prev. Vet. Med. $71: 11-21$.

Somers, J. G. C. J., K. Frankena, E. N. Noordhuizen-Stassen, and J. H. M. Metz. 2005b. Risk factors for interdigital dermatitis and heel erosion in dairy cows kept in cubicle houses in the Netherlands. Prev. Vet. Med. 71:23-34.

Van der Walle, K. 2004. Gebruikswaarde van melkvee (Values in use of dairy cattle). Animal Sciences Group Wageningen UR, Lelystad, the Netherlands.

Warnick, L. D., D. Janssen, C. L. Guard, and Y. T. Grohn. 2001. The effect of lameness on milk production in dairy cows. J. Dairy Sci 84:1988-1997.

Whay, H. R., D. C. J. Main, L. E. Green, and A. J. F. Webster 2003. Assessment of the welfare of dairy cattle using animal-based measurements: Direct observations and investigation of farm records. Vet. Rec. 153:197-202.

Whitaker, D. A., A. I. Macrae, and E. Burrough. 2004. Disposal and disease rates in British dairy herds between April 1998 and March 2002. Vet. Rec. 155:43-47.

Wood, P. D. P. 1967. Algebraic model of the lactation curve in cattle. Nature 216:164-165. 